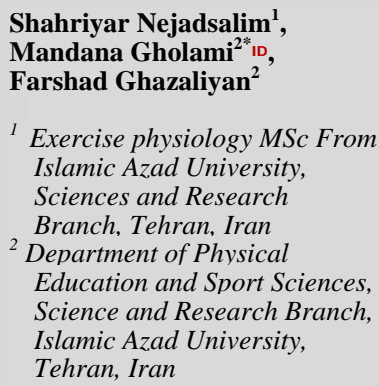

Shahriyar Nejadsalim ${ }^{1}$, Mandana Gholami ${ }^{2 *}{ }_{\text {ID, }}$ Farshad Ghazaliyan ${ }^{2}$

${ }^{1}$ Exercise physiology MSc From Islamic Azad University, Sciences and Research Branch, Tehran, Iran

${ }^{2}$ Department of Physical Education and Sport Sciences, Science and Research Branch, Islamic Azad University, Tehran, Iran

\section{Effect of Eight Weeks' Resistance Training on Serum Levels of Irisin and Lipid Profile in Overweight Men's with Nonalcoholic Fatty Liver Disease}

Received:1 Dec. 2017 ; Accepted: 9 Jan. 2018

Background: Exercise training have a positive effect on nonalcoholic fatty liver disease (NAFLD). However, effectiveness pathways of exercise training on NAFLD is unknown. Therefore, the present study was conducted to aim of investigate the effect of eight weeks' resistance training on serum levels of irisin and lipid profile in overweight men's with nonalcoholic fatty liver disease.

Methods: This study subjects consist of 30 overweight men's afflicted by NAFLD with average age $40.2 \pm 2.5$ and weight $75.5 \pm 3.19$, that randomly assigned in control $(n=15)$ and resistance training $(\mathrm{n}=15)$ groups. Resistance training program performed for eight weeks and three sessions in week. Training load from 40 percent of $1 \mathrm{RM}$ in first week increased to 70 percent of $1 \mathrm{RM}$ in last week. 48 hours after last exercise session, blood samples collected and given variables measured and data were analyzed by means of SPSS-24 software and analyze covariance (ANCOVA) test.

Results: Results indicated significant increase of irisin and HDL $(p=0.001)$ and significant decrease in LDL, TG and cholesterol $(p=0.001)$ in resistance training group compared to control group.

Conclusions: It seems that, some of positive effect of resistance training in patient with NAFLD can be attributed to increase irisin levels and resistance training can play important role in modulate lipid profile in this patient.

Keywords: Fatty liver, Resistance training, Irisin, Lipid profile 


\section{تأثير هشت هفته تمرين مقاومتى بر سطوح سرمى آيريزين و نيمرخ ليييدى در

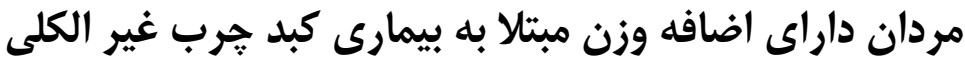

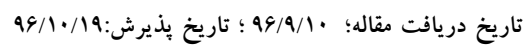

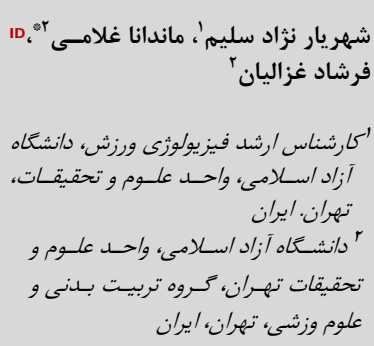

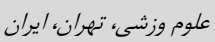

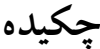

زمينه و هدف: تمرينات ورزشى داراى تاثيرات مثبتى بر بيمارى كبد جرب غير الكلى (NAFLD) اسـت. بـا وجـود ايـن، مسيرهاى اثر كذارى تمرينات ورزشى بر NAFLD مشخص نيست. از اين رو، يثزوهش حاضر با هدف بررسى تاثير هشـت هفته تمرين مقاومتى بر سطوح سرمى آيريزين و نيمرخ ليبيدى در مردان داراى اضافه وزن مبتلا به بيمارى كبد جرب غيـر الكلى انجام شد.

مواد و روش ها: آزمودنى هاى يثزوهش حاضر را •r مرد داراى اضافه وزن مبتلا به NAFLD با ميانخين سنى و وزن كرفتند. برنامه تمرين مقاومتى به مدت هشت هفته و هفتهاى سه جلسه انجام شد. بار تمرين از •ب درصــ 1RM در هفتـه اول به •V درصد 1RM در هفته آخر افزايش يافت. برا ساعت بعد از جلسه آخر تمرين، نمونههـاى خـونى جمـع آورى و متغيرهاى مورد نظر سنجيده شدند و دادهها با نرم افـزار SPSS-24و آزمـون آنـاليز كوواريـانس (ANCOVA) تجزيسه و تحليل شد. يافتها: نتايج افزايش معنادار آيريزين و HDL (1 HDL LDL را در گروه تمرين مقاومتى در مقايسه با گروه كنترل نشان داد. نتيجه گيرى: به نظر مىرسد كه بخشى از تاثيرات مثبت تمرينات مقاومتى در بيمـاران مبـتلا بـه NAFLD را مسىتـوان بـه. افزايش سطوح آيريزين نسبت داد و تمرينات مقاومتى مىتواند نقش مهمى در تعديل نيمرخ ليبيد اين بيماران داشته باشد. كلمات كليدى: كبد جرب، تمرين مقاومتى، آيريزين، نيمرخ ليبيدى

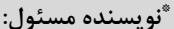

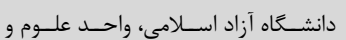

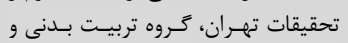
علوم وزشى، تهران، ايران

$.9|r-| \& q 1 \Lambda 9 \Lambda$

E-mail:m.gholami@srbiau.ac.ir 
استئاتوز كبدى بيشخيرى مى كند كه اين تاثير تمرينات ورزشى را بــهـ

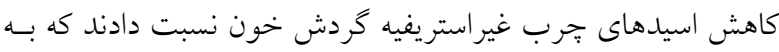
احتمـال زيـاد از افزايش اكسيداسـيون محيطى ناشسى مسىشـود." على رغم اينكه نقش مثبت انواع مختلف تمرينات ورزشى در بهبـود

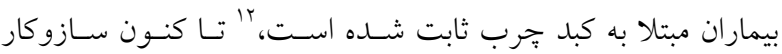

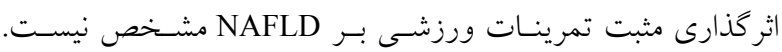

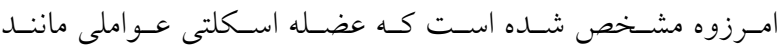

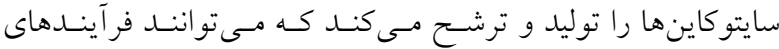

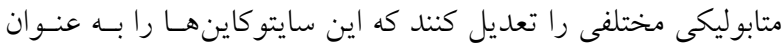

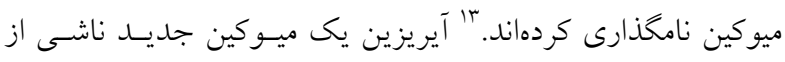

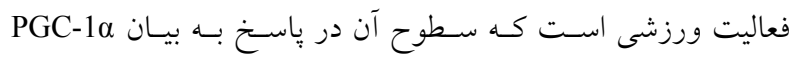

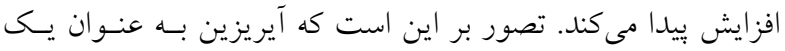

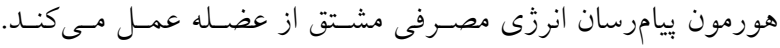

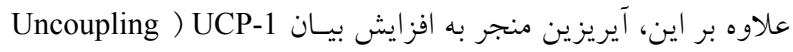

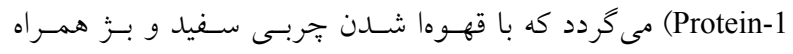

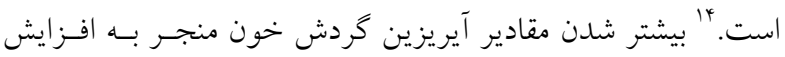
اكسيزن مصرفى، بهبود تحمل كلوكز و حساسيت انسولين مىشود و

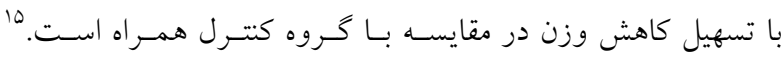

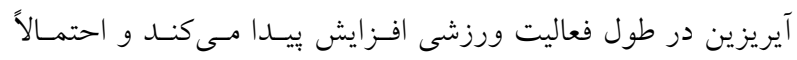

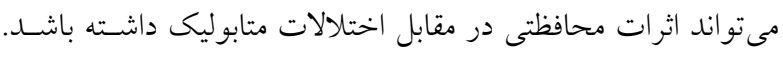

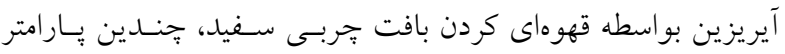

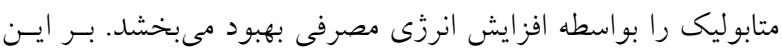

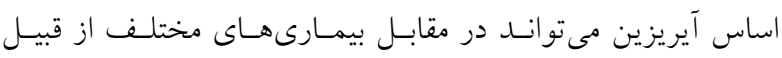

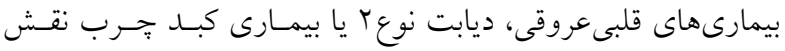

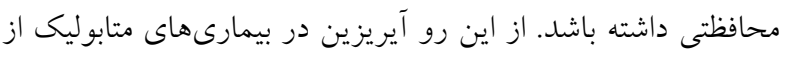

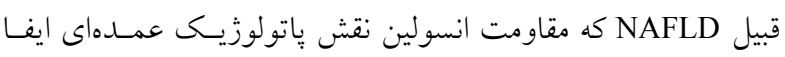

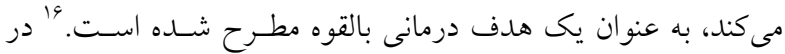

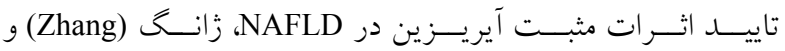

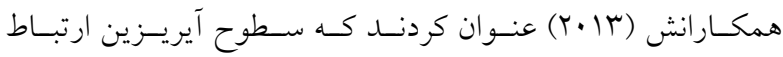

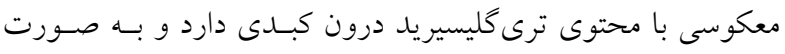

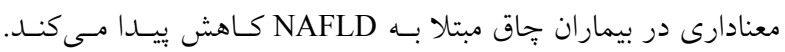
همجنين، كاهش تدريجى آيريزين با افزايش محتوى ترى كليسيريد

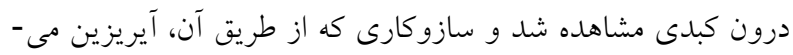

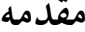

جاقى و اضافه وزن با شيوع ديابت نوع r و يرفشار خونى همراه

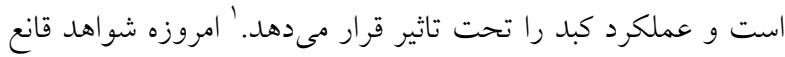

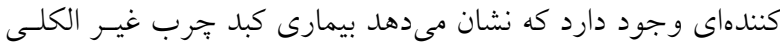
بخشى از سـندرم (Non-alcoholic fatty liver disease) (NAFLD) متابوليك است و در حقيقت، بخـش عمــداى از بيمـاران مبـتلا بـهـ

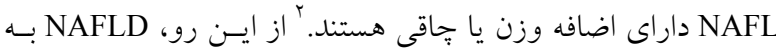

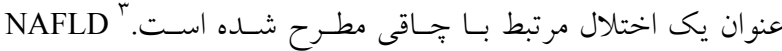

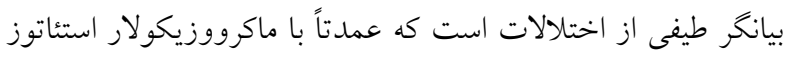
كبدى (Macrovesicular Hepatic Steatosis) مشخص مى شـود كـه

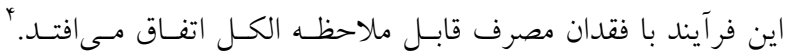
NAFLD حدود ها - •r درصد جمعيت عمومى را تحت تاثير قـرار مى دهد و ميزان شيوع آن در افراد جاق و مبتلا به ديابت نوعج بــيش

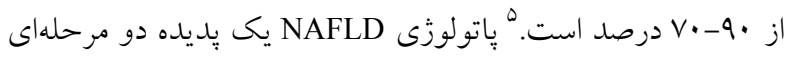

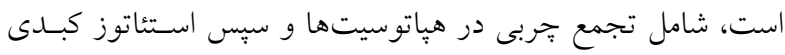

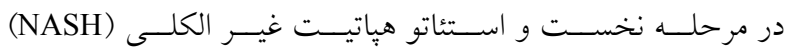
(Nonalcoholic Steatohepatitis)

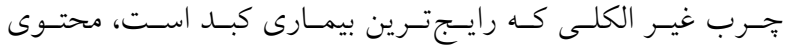

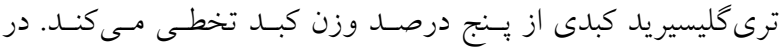

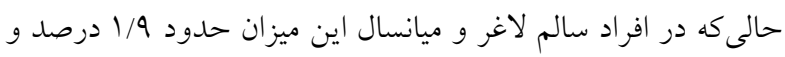

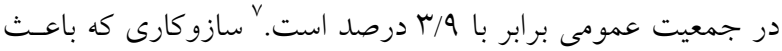
تجمع خربى در كبد مىشود مىتواند ناشسى از خربسى مـازاد رزيسم غذايى، افزايش تحويل اسيدهاى جرب به كبد، اكسيداسيون ناكـافى

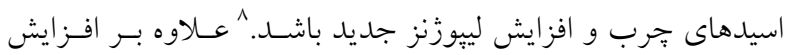
محتوى ترى گليسيريد كبدى در NAFLD، نيمرخ ليبيدى اين بيماران

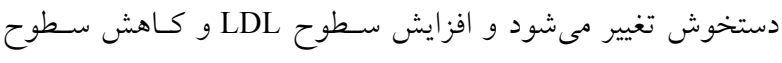
HDL را در اين بيمار ان كزارش كردهاند.

تاثير ثابت شده فعاليت جسمانى و تمرينات ورزشسى بـر ابعـاد

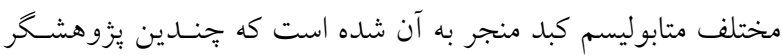

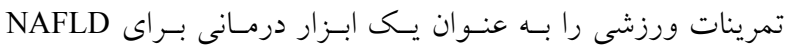
توصيه كنند." در تاييد اين كفتهها، كزارش شده است كه تمرينـات

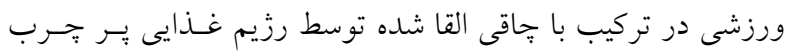
به مدت هشت هفته در رتها به صـورت كامـل از مـاكرووزيكولار 
برنامه عادى روزانه مانند كذشـته را ادامـه دادنـــ. در طـول اجـــاى يزوهش، اصول اخلاقى رعايت شد و كليه مراحل بـرزوهش حاضـر

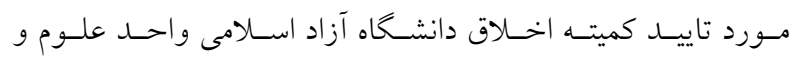
تحقيقات بود.

\section{برنامه تمرين مقاومتى}

آزمودنى هاى گروه تمرين، به مدت هشت هفته و هر هفتـه ســـ

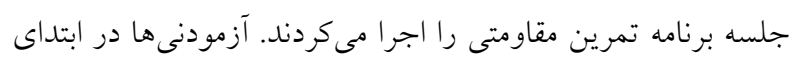

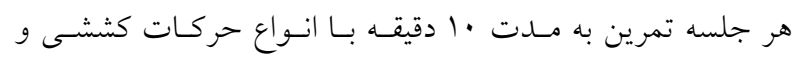

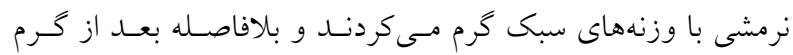

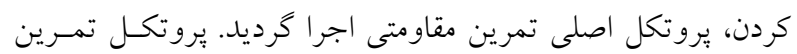

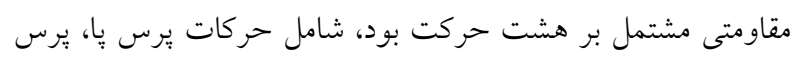

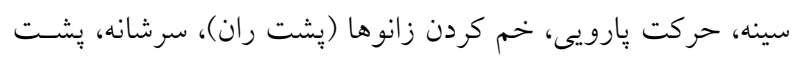

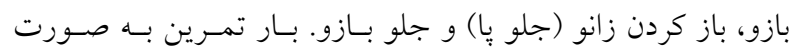

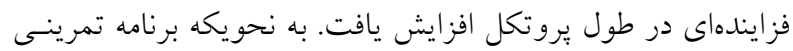

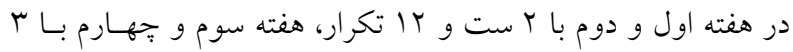
ست و • ا تكرار، هفته ينجم و ششم با س سـت و 1 تكــرار و هفتـه

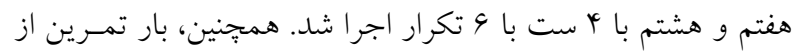

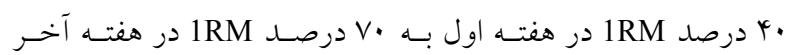
رسيد (هر دو هفته ·ل درصد 1RM به بار تمرين افزوده مىشد). در

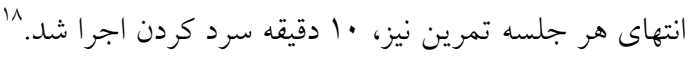

\section{سنجش و بررسى متغيرهاى مورد مطالعه}

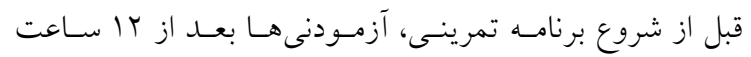

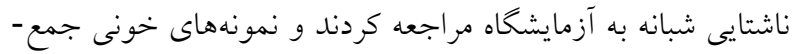

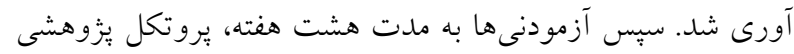

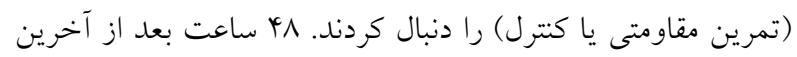

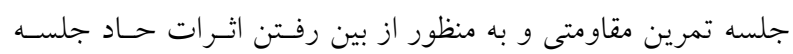

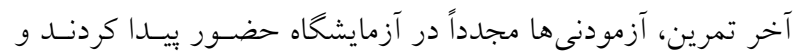

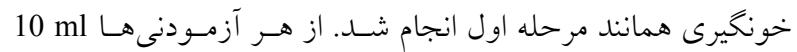

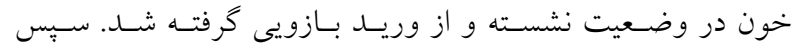

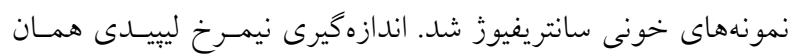

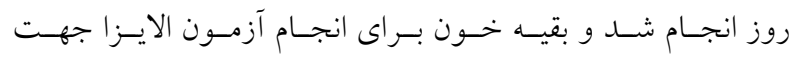

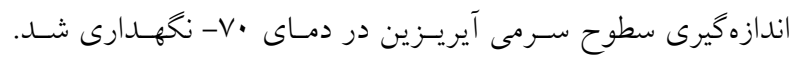

تواند از تجمع ترى كليسيريدهاى كبدى بيشخيرى كند، ممكن اسـت مستقيم يا غير مستقيم باشد.

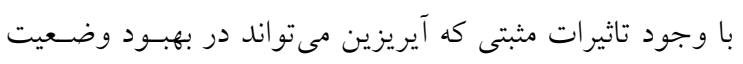
متابوليسم و مقابله با اختلالات متابوليك داشته باشد و تـاثير بـالقوه تمرينات ورزشى مختلف در افـزايش سـطوح ايسن ميـوكين، هنـوز تغييرات سطوح آيريزين به دنبال تمرينات ورزشى در بيماران مبـتلا

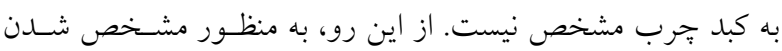
مسيرهاى اثر كذارى تمرينـات ورزشـى در بيمـاران مبـتلا NAFL و

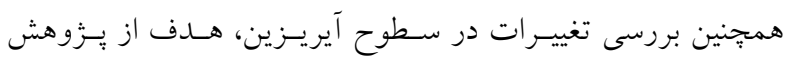

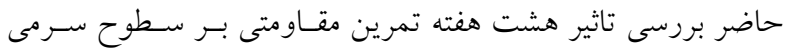

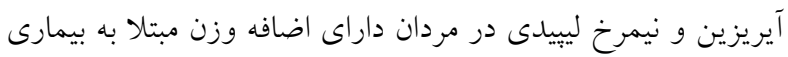

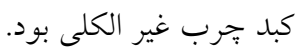

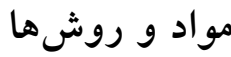

جامعه آمارى بزّوهش حاضر را مردان جاق و داراى اضافه وزن مبتلا به بيمارى كبد جرب غيرالكلى (NAFLD) شهر تهران تشـكيل

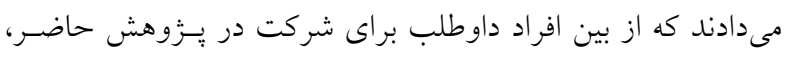

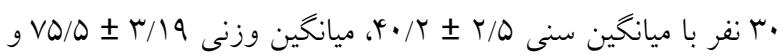

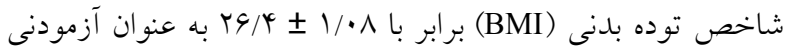

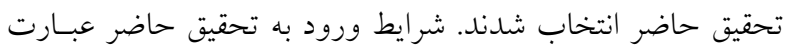
بود از BMI بالاتر از هT، عدم شركت در تمرينـات ورزشسى مـنظم

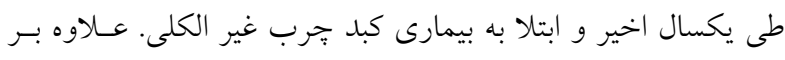

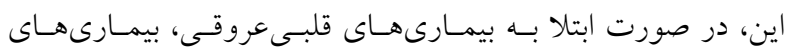

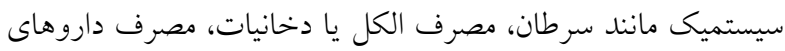

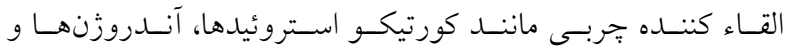
استروزنهاى مصنوعى و يا شركت در تمرينات ورزشى مـنظم طى سلى سال كذشته، افراد داوطلب از تحقيق حاضر كنار كذاشته مسى شــــند.

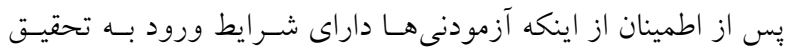
حاضر هستند و مشكلى براى شركت در يروتكـل يزوهشى بـ حاضـر

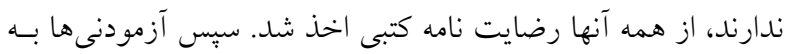
صورت تصادفى در دو گروه ها تايى شامل گروه تمرين مقاومتى و

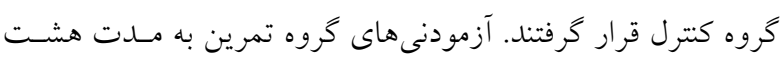

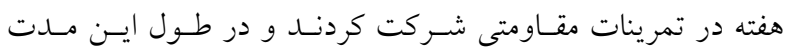
آزمودنى هاى گروه كنترل در هيج برنامه تمرينى شـركت نداشـتند و 
آزمون t مستقل استفاده شد و آلفا در سطح ه • • در نظر گرفته شد.

نتايج دادههاى مربوط به سن و قد آزمـودنىهـا در دو گـروه تمـرين

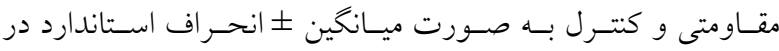
جدول ا ارائه شده است. نتايج آزمون t وابسته به منظور مقايسه تغييـرات درون خروهـى

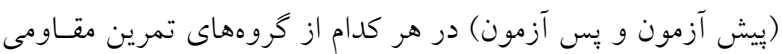
و كنترل و همجنين نتايج آزمون t مستقل براى مقايسه تغييرات بسين كروهى (تمرين مقاومتى و كنترل) بـراى سـطوح سـرمى آيريسزين،

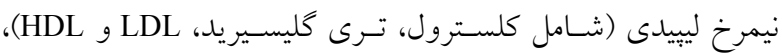
وزن بدن و BMI در جدول ب ارائه شده است. نتايج ارائسه شـده بـــ صورت ميانخين \pm انحر اف استاندارد است. جدول ا: سن و قد آزمودنىها در گروه تمرين مقاومتى و كتترل (ميانگين \pm انحراف استاندارد)

\begin{tabular}{|c|c|c|}
\hline كنترل & تمرين مقاومتى & متغير \\
\hline$r \cdot / r \pm r / \Delta$ & $r \cdot / 1 \pm r / 19$ & سن (سال) \\
\hline$|V| / Q \pm r / \varphi$ & $|V r / r \pm r /|$ & قد (سانتى متر) \\
\hline
\end{tabular}

جدول Y: دادههاى مربوط به متغيرهاى بزّوهش به صورت ميانخين \pm انحراف استاندارد در مرحله يبش آزمون و يس آزمون

\begin{tabular}{|c|c|c|c|c|c|}
\hline 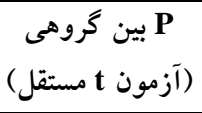 & 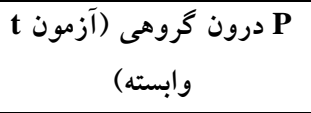 & يس آزمون & ي بيش آزمون & كروههاى بزوهشى & متغير \\
\hline \multirow[t]{2}{*}{$* \cdot / \cdots$} & $\cdot / \pi 1$ & $111 / 9 \pm 9 / r$ & $111 V / 9 \pm 11 / 4$ & كروه كتترل & آيريزين (ng/ml) \\
\hline & $\# \cdot / \cdot \cdot v$ & $r I \cdot / 0 \pm I V / \Lambda$ & $|V q / r \pm| r / q$ & گروه تمرين & \\
\hline \multirow[t]{2}{*}{$* \cdot / \cdot+1$} & $\cdot / 4 \Lambda$ & $r g 1 / r \pm r r / V$ & $r \Delta r / l \pm r I / \kappa$ & كروه كتترل & كلسترول (mg/dl) \\
\hline & $\# \cdot / \cdots$ & $r \mid N / r \pm 19 / 9$ & TYT/V $\pm 19 / V$ & كروه تمرين & \\
\hline \multirow[t]{2}{*}{$* / \cdots$} &.$/ .9$ & $r \Psi r / l \pm r q / r$ & $M M Y / D \pm T r / r$ & كروه كنترل & ترى كليسيريد (mg/dl) \\
\hline & $\# \cdot / \cdots$ & $199 / 4 \pm r r / V$ & $r T V / \Lambda \pm r Q / \Lambda$ & گروه تمرين & \\
\hline \multirow[t]{2}{*}{$* \cdot / \cdot 1$} & $\cdot / \Lambda$ & $\kappa V / \Lambda \pm Q / \Lambda$ & $\varphi \& / \varphi \pm r / r$ & كروه كتترل & $(\mathrm{mg} / \mathrm{dl}) \mathrm{HDL}$ \\
\hline & $\# \cdot / \cdot r$ & $\Delta 1 / \Lambda \pm V / 4$ & $\Psi Q / \cdot \pm Q / Y$ & گروه تمرين & \\
\hline \multirow[t]{2}{*}{$* / \cdots$} & $\cdot / 1 \cdot 4$ & $r \cdot q / r \pm r V / l$ & $r \cdot I / r \pm r r / V$ & كروه كنترل & $(\mathrm{mg} / \mathrm{dl}) \mathrm{LDL}$ \\
\hline & $\# \cdot / \cdot \cdot 1$ & $194 / 9 \pm 14 / 9$ & $1 / 9 / 0 \pm 1 / / 4$ & گروه تمرين & \\
\hline \multirow[t]{2}{*}{$\cdot / \mu$} & $\cdot / Q r$ & $r \in / r \pm r / \Lambda$ & $r \varphi / r \pm r / l$ & كروه كنترل & $\begin{array}{r}\mathrm{BMI} \\
\left(\mathrm{kg} / \mathrm{m}^{2}\right)\end{array}$ \\
\hline & $\cdot / 79$ & $r q / 9 \pm 1 / 4$ & $r V / \Psi \pm r / \varphi$ & كروه تمرين & \\
\hline \multirow[t]{2}{*}{$\cdot / \mu^{4}$} & $\cdot / 01$ & $V Q / r \pm r / r$ & $V \Psi / r \pm r / l$ & كروه كتترل & وزن بدن (كيلو گرم) \\
\hline & $\cdot / 94$ & $v G / 4 \pm r / 1$ & $V Q / 4 \pm \Gamma / r$ & كروه تمرين & \\
\hline
\end{tabular}


جدول س: تغييرات در مقادير 1RM حركات مختلف بعد از هشت هفته تمرين مقاومتى در گروه تمرين مقاومتى و كنترل

\begin{tabular}{|c|c|c|c|c|c|}
\hline 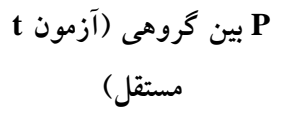 & $\begin{array}{l}\text { P درون گروهى } \mathbf{P} \text { (آزمون t وابسته) }\end{array}$ & يس آزمون & بيش آزمون & كروههاى يثر & لرمتى \\
\hline \multirow[t]{2}{*}{$* \cdot / \cdots$} & $\cdot / \& V$ & $1 \cdot 1 / 9 \pm 18 / 1$ & $1 \cdot 9 / 0 \pm r 1 / 9$ & كروه كنترل & يرس پِا \\
\hline & $\# \cdot / \cdots$ & $\mid r r / Y \pm T r / q$ & $111 / 4 \pm 19 / r$ & كروه تمرين & \\
\hline \multirow[t]{2}{*}{$\cdot / \cdot v 1$} & $\cdot / T r$ & $\Delta r / \Lambda \pm 1 \cdot / r$ & $01 / 9 \pm 1 r / 9$ & كروه كنترل & يرس سينه \\
\hline & $\# \cdot / \cdot 1$ & $91 / 1 \pm 11 / 2$ & $r q / v \pm q / r$ & كروه تمرين & \\
\hline \multirow[t]{2}{*}{$* \cdot / \cdots$} &.$/ 90$ & $F V / D \pm q / \varphi$ & $Y \psi / T \pm \| / \Lambda$ & كروه كنترل & يارويى نشسته \\
\hline & $\# \cdot / \cdots$ & $\Delta G / \Gamma \pm \Lambda / q$ & $r \mid / r \pm 1 \cdot / r$ & كروه تمرين & \\
\hline \multirow[t]{2}{*}{$\cdot / \mathrm{IV}$} & $\cdot / 09$ & $r 4 / 1 \pm 9 / r$ & $\Pi r / v \pm V$ & كروه كنترل & يشت ران \\
\hline &.$/ 11$ & $\mu \psi / \Delta \pm \Lambda / \varphi$ & $r N / \varphi^{c} \pm 9 / 9$ & كروه تمرين & \\
\hline \multirow[t]{2}{*}{$* \cdot / \cdot r$} & $\cdot / V^{4}$ & $r r / q \pm 1 \cdot / \Lambda$ & $r q / 1 \pm 0 / r$ & كروه كنترل & سر شانه \\
\hline &.$/ .9$ & $r \cdot / r \pm \Lambda / r$ & $r Y / q \pm V / \Lambda$ & كروه تمرين & \\
\hline \multirow[t]{2}{*}{$\cdot / T Q$} & $\cdot / \mu \wedge$ & $r Q / \Lambda \pm r / \Lambda$ & $r r / \cdot \pm \Delta / \varphi$ & كروه كنترل & يشت بازو \\
\hline & $\cdot / 14$ & $r \& / V \pm 9 / 0$ & $r \mid / 9 \pm r / 9$ & كروه تمرين & \\
\hline \multirow[t]{2}{*}{$* \cdot \cdots$} & $\cdot / \wedge \Delta$ & $k r / r \pm \mid r / v$ & $r \& / \Lambda \pm \mid r / \Lambda$ & كروه كنترل & جلو پِا \\
\hline & $\# \cdot / \cdots$ & $94 / \mu \pm 19 / 4$ & $0 . / 1 \pm 1 \pi / 9$ & كروه تمرين & \\
\hline \multirow[t]{2}{*}{$\cdot / \cdots 1$} & $\cdot / \pi q$ & $r q / 4 \pm q / r$ & $r Q / r \pm \Lambda / l$ & كروه كنترل & جلو بازو \\
\hline & $\# \cdot / \cdots r$ & $M Y / \Lambda \pm Q / \Lambda$ & $r V / 9 \pm 9 / V$ & كروه تمرين & \\
\hline
\end{tabular}

تمرين مقاومتى وجود دارد. بر مبنـاى يافتـههـاى يـزوهش حاضـر،

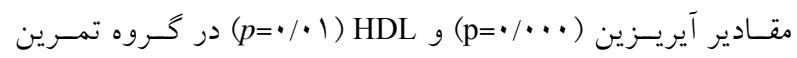
مقاومتى در مقايسه با گروه كنترل به صورت معنادارى افزايش يافتـه

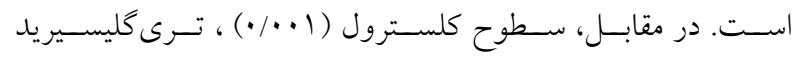

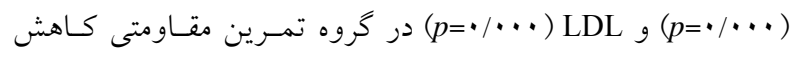
معنادارى را در مقايسه با گروه كتترل نشان داد. با وجود اين، نتـايج

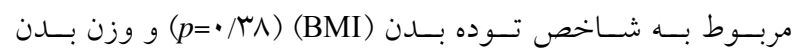

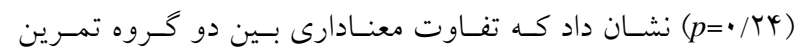
مقاومتى و كنترل وجود ندارد (جدول Y Y). تغييرات در قدرت يك تكـرار بيشـينه (1RM) آزمـودنىهـا در

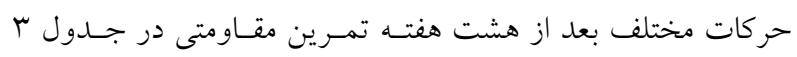

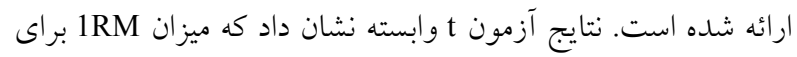

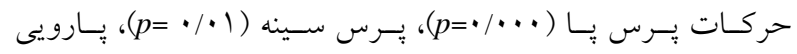

تجزيه و تحليل دادهها با آزمون t وابسـته نشـان داد كـه بعـد از

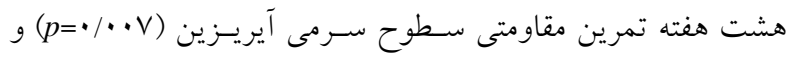

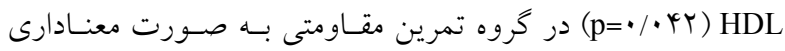
افزايش يافته است. همخنين، كاهش مقـادير كلسـترول ( ( •/ (p)،

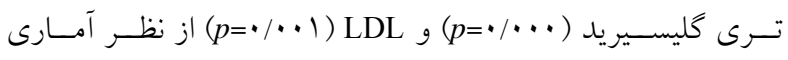
معنادار بود. اما، تغييرات BMI و وزن بلدن بعد از هشت هفته تمرين

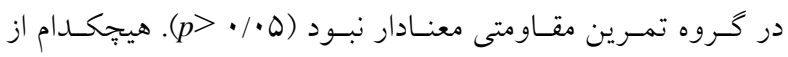

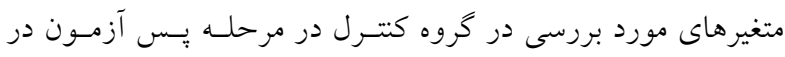

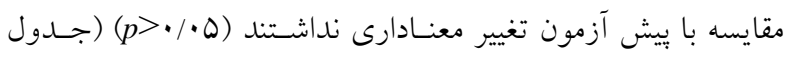
علاوه بر اين، تجزيه و تحليل دادهها با آزمون t مستقل نشان داد كه بعد از هشت هفته تمرين مقاومتى تفاوت معنادارى بـين سـطوح آيريزين، كلسترول، ترى گليسيريد، LDL و HDL در گروه كتترل و 
شامل تمرين استقامتى "10 و مقاومتى بr را در افزايش سطوح آيريـزين

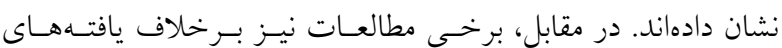

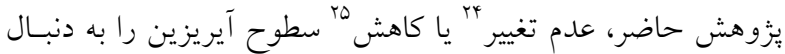

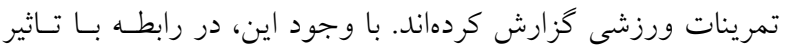
تمرينات ورزشى بر سـوح آيريسزين در بيمـاران مبـتلا بـه NAFL اطلاعى در دست نيست. اما با توجه به نتايج يزوهش حاضر به نظر

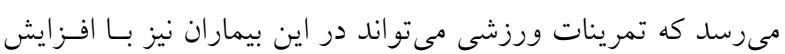
سطوح آيريزين همـراه باشـــ. زائسو (Yhao) و همكـارانش (Y.IV) همسو با نتايج مطالعه حاضر نشان دادند كه Y I هفته تمرين مقاومتى

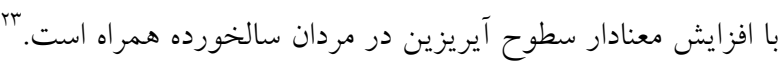
اين نتايج مشابه علىرغم مدت زمان كمتر برنامه تمرينى در بزوهش حاضر و نوع متفاوت آزمودنى ها مشاهده شد. كيم (Kim) و همكارانش (Y.19) در بزّوهشى كه از نظر مــدت زمان دوره تمرينى مشابه با يـرزوهش حاضـر بـود بـهـ مقايسـه تـاثير هشت هفته تمرين استقامتى و مقاومتى بر مقادير آيريزين تِرداختنـد.

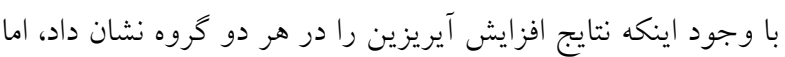

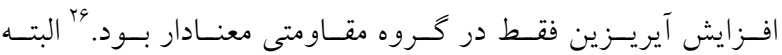
آزمودنى هاى كيم و همكار انش (19 (Y) سالم بودند و يزوهش روى هر دو جــس (زن و مـرد) انجـام شـده بـود. توجيـا (Tsuchiya) و

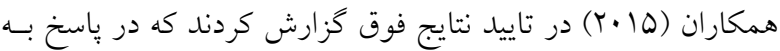
تمرينـات مقــاومتى در مقايسـه بـا تمرينـات اسـتقامتى و تمرينـات

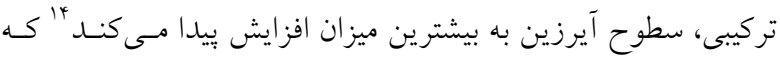

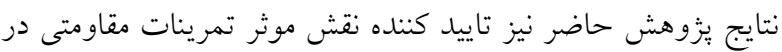

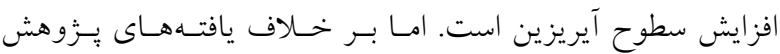

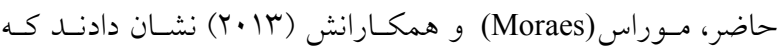
شش ماه تمرينات مقـاومتى بـا تغييـر سـطوح آيريسزين در بيمـاران

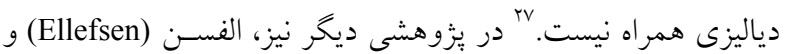

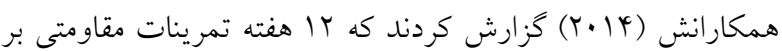

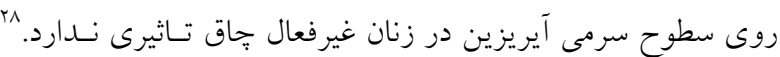
تفاوت در يافتهاى فوق بـا نتـايج حاضـر را مسى تـوان بـهـ عوامـل

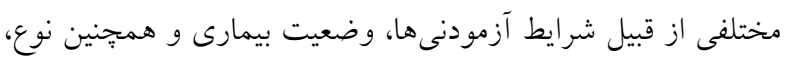
شدت، مدت و حجم متفاوت برنامه تمرينسى مـورد اسـتفاده نسـبت

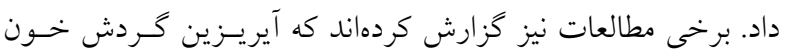

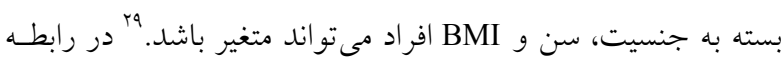

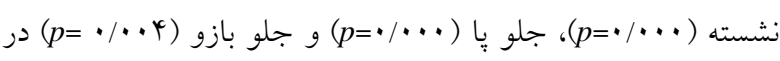

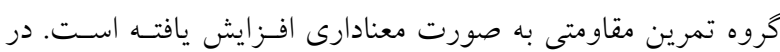

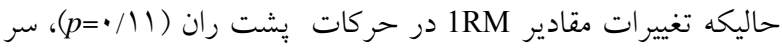
شانه (q•/ حركت ذكر شده (يشت ران، سر شانه و يشت بازو) افـزايش نسـبى 1RM بعد از هشت هفته تمـرين مقـاومتى مشـاهده شــــ تغييـرات

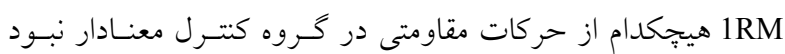

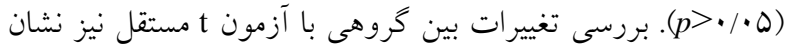
داد كه افزايش 1RM در حركات يُرس بِا، پِارويى نشسـته، سرشـانه،

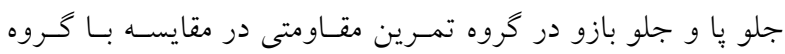

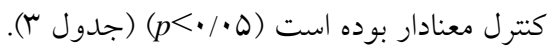

هدف از اجراى يزوهش حاضر، بررسى تاثير هشت هفته تمرين

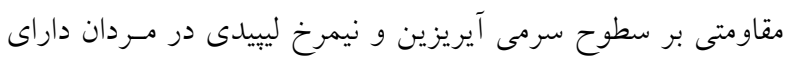

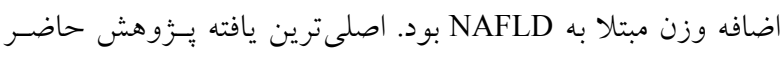

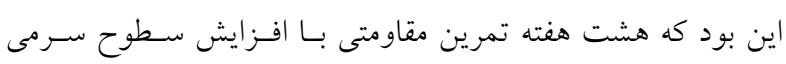
آيريزين و بهبود نيمرخ ليبيدى در مردان مبـتلا بـه NAFLD همـراه است. عضله اسكلتى در يّاسخ به انقباضات عضلانى در طول فعاليت

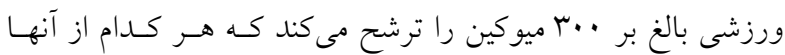

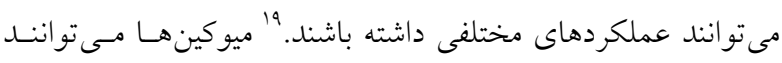
اثرات متابوليكى مفيدى را در طول ارتباط بين عضله اسكلتى و كبــ مديد و همجنين عضله اسكلتى و بافت جربسى فـراهم كنتـد. بـه عـلاوه، ميو كينها اثرات مثبتى بر روى برداشت كلوكز، تحمل كلوكز، تنظيم

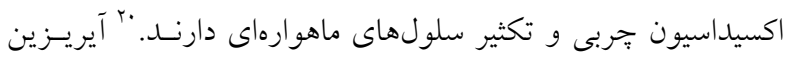
يكى از ميوكينهايى است كه جديداً شناسايى شـده اسـت و اعتقــاد

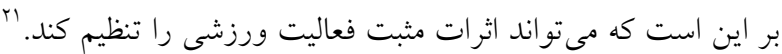

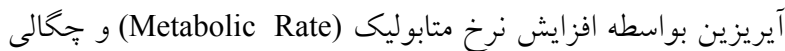

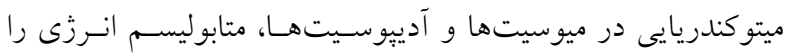
تنظيم مى كند و مىتواند در بيمارىهاى متابوليك نقـش مهمسى ايفـا

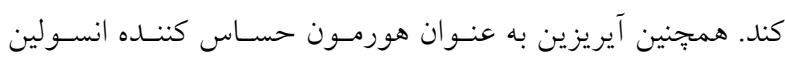

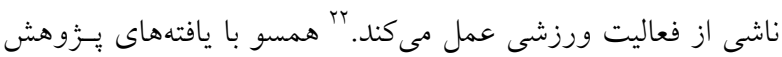

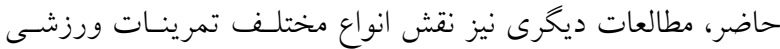


بافت جربى سفيد مىشود. آير يزين همجنـين از طريـق القـاى بيـان

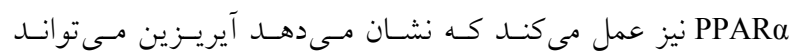

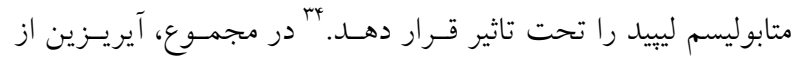
طريق افزايش بيـان UCP-1 و فعـال كردن مسيرهاى سيخنالينگ

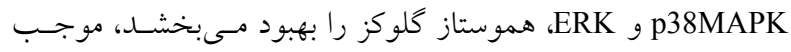

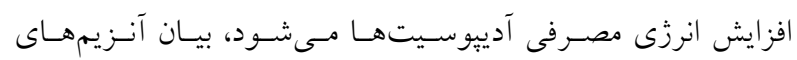

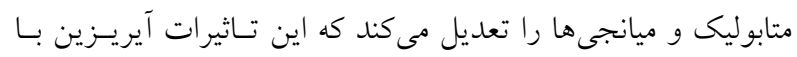

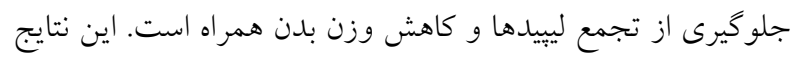

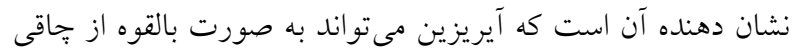

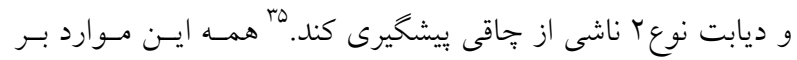

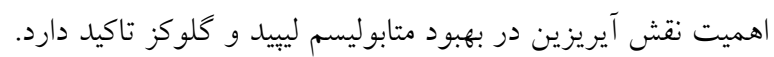

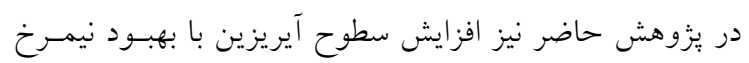

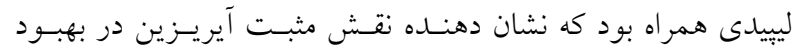

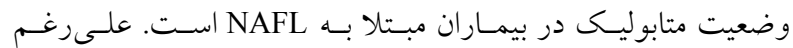
يافتهاى يزوهش حاضر، به منظور بررسى مسـيرهاى تاثير كــارى انواع مختلف تمرينات ورزشى بـر بيمـارى NAFL، بايــــ مطالعـات

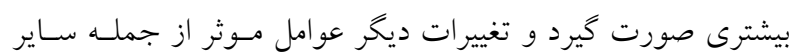
ميوكينها نيز مورد بررسى قرار كيرد.

\section{نتيجه كيرى}

بر مبناى يافتهاى يزّوهش حاضر، مىتـوان نتيجـه كرفـت كـه

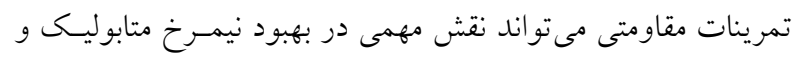

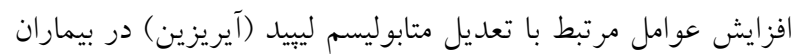
مبتلا به كبد جرب غير الكلى داشته باشد. البته به منظور بيشخيرى از

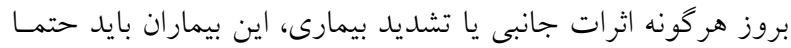
در طول تمرينات ورزشى با يزشك خود در ارتباط باشند.

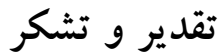

تحقيق حاضر حاصل يافتههاى بايان نامه كارشناسى ارشد رشته

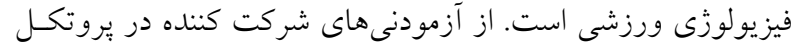

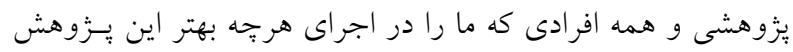
يارى نمودند، نهايت تشكر را داريم.

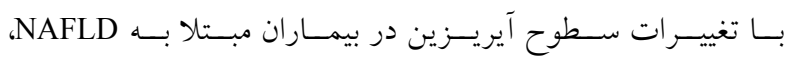

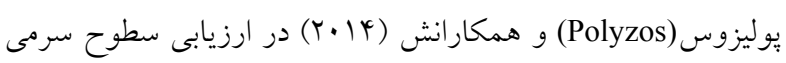

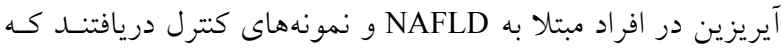

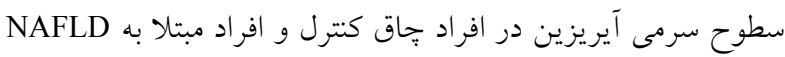

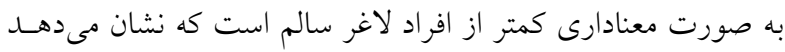

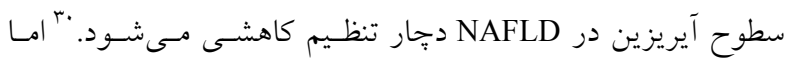

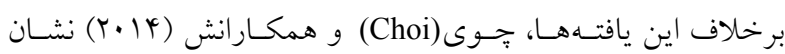

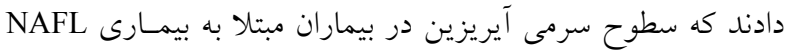

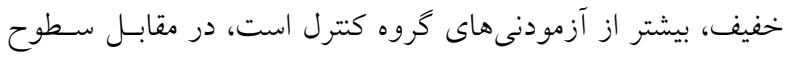

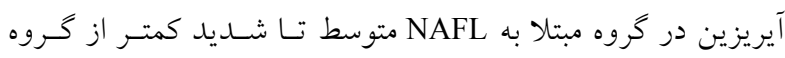

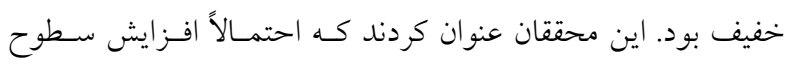

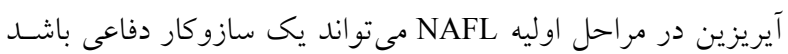

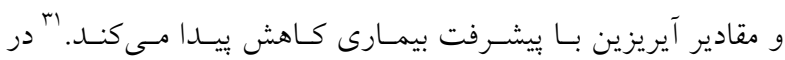
يُزوهشى مشابه با يُزوهش حاضر، محققان نشان دادنــ كـه م هفتـهـ

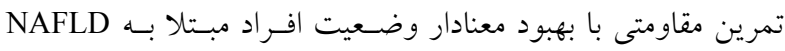

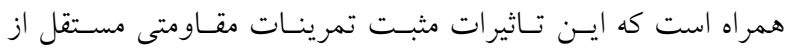

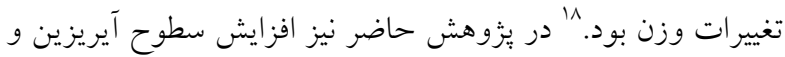
بهبود نيمرخ ليبيدى مستقل از تغييرات وزن مشاهده شد. در رابطه با فيا

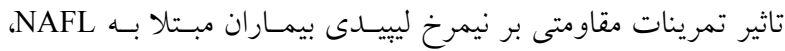

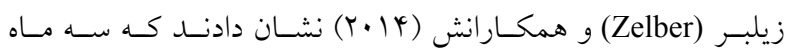

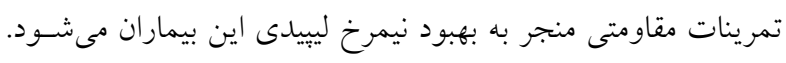

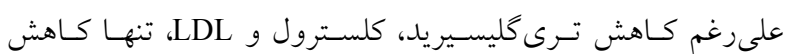

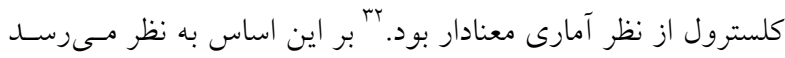

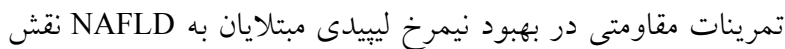

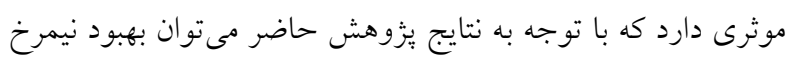

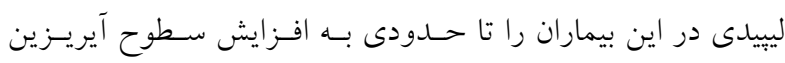

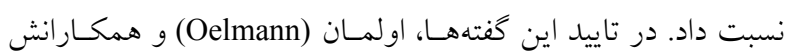
(Y.19) نشان دادند كه بين سطوح آيريزين و نيمرخ ليـدى ارتبـاط وجود دارد. بر مبناى نتايج اين محققان، ارتباط معكوسى بين سطوح

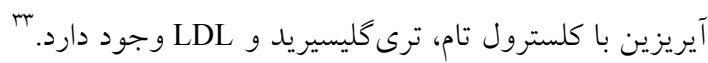

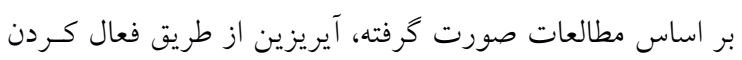

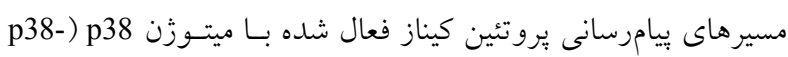
(P38- Mitogen-activated Protein Kinases) (MAPK وابسته به يِيامرسانى خارج سلولى (ERK) منجر بـهـ قهوماى شـدن 


\section{References}

1.Després JP, Lemieux I. Abdominal obesity and metabolic syndrome. Nature. 2006. 444(7121): 881-7.

2.Tilg H, Moschen AR. Insulin resistance, inflammation, and non-alcoholic fatty liver disease. Trends in Endocrinology \& Metabolism. 2008. 19(10):371-9.

3. Gentile CL, Pagliassotti MJ. The role of fatty acids in the development and progression of nonalcoholic fatty liver disease. The Journal of nutritional biochemistry. 2008. 19(9):567-76.

4. Petta S, Muratore C, Craxi A. Non-alcoholic fatty liver disease pathogenesis: the present and the future. Digestive and Liver Disease. 2009. 41(9):615-25.

5. Targher G, Arcaro G. Non-alcoholic fatty liver disease and increased risk of cardiovascular disease. Atherosclerosis. 2007. 191(2):235-40.

6. Daneshi-Maskooni M, Keshavarz SA, Mansouri S, Qorbani M, Alavian SM, Badri-Fariman M, et al. The effects of green cardamom on blood glucose indices, lipids, inflammatory factors, paraxonase- 1 , sirtuin- 1 , and irisin in patients with nonalcoholic fatty liver disease and obesity: study protocol for a randomized controlled trial. Trials. 2017; 18(1):260.

7. Tessari P, Coracina A, Cosma A, Tiengo A. Hepatic lipid metabolism and non-alcoholic fatty liver disease. Nutrition, Metabolism and Cardiovascular Diseases. 2009. 19(4):291-302.

8. Mo L, Shen J, Liu Q, Zhang Y, Kuang J, Pu S, Cheng S, Zou M, Jiang W, Jiang $\mathrm{C}, \mathrm{Qu} \mathrm{A}$. Irisin is regulated by CAR in liver and is a mediator of hepatic glucose and lipid metabolism. Molecular Endocrinology. 2016. 30(5):533-42.

9. Cali AM, Zern TL, Taksali SE, De Oliveira AM, Dufour S, Otvos JD, et al. Intrahepatic fat accumulation and alterations in lipoprotein composition in obese adolescents. Diabetes care. 2007. 30(12):3093-8.

10. Bergasa NV, Mehlman J, Bir K. Aerobic exercise: a potential therapeutic intervention for patients with liver disease. Medical hypotheses. 2004. 62(6):935-41.

11. Gauthier MS, Couturier K, Latour JG, Lavoie JM. Concurrent exercise prevents high-fat-diet-induced macrovesicular hepatic steatosis. Journal of Applied Physiology. 2003. 94(6):2127-34.

12. Keating SE, Hackett DA, George J, Johnson NA. Exercise and non-alcoholic fatty liver disease: a systematic review and meta-analysis. Journal of hepatology. 2012. 57(1):157-66

13. Sanchis-Gomar F, Alis R, Pareja-Galeano H, Sola E, Victor VM, Rocha M, et al. Circulating irisin levels are not correlated with BMI, age, and other biological parameters in obese and diabetic patients. Endocrine. 2014. 46(3):674-7.
14. Tsuchiya Y, Ando D, Takamatsu K, Goto K. Resistance exercise induces a greater irisin response than endurance exercise. Metabolism. 2015. 64(9):1042-50.

15. Boström P, Wu J, Jedrychowski MP, Korde A, Ye L, Lo $\mathrm{JC}$, et al. A PGC1- $\alpha$ dependent myokine that drives brown-fat-like development of white fat and thermogenesis. Nature. 2012. 481(7382):463-8.

16. Arias-Loste MT, Ranchal I, Romero-Gómez M, Crespo J. Irisin, a link among fatty liver disease, physical inactivity and insulin resistance. International journal of molecular sciences. 2014. 15(12):23163-78.

17. Zhang HJ, Zhang XF, Ma ZM, Pan LL, Chen Z, Han HW, Han CK, Zhuang XJ, Lu Y, Li XJ, Yang SY. Irisin is inversely associated with intrahepatic triglyceride contents in obese adults. Journal of hepatology. 2013. 59(3):557-62.

18. Hallsworth K, Fattakhova G, Hollingsworth KG, Thoma $\mathrm{C}$, Moore S, Taylor R, et al. Resistance exercise reduces liver fat and its mediators in non-alcoholic fatty liver disease independent of weight loss. Gut. 2011. 60(9):1278-83

19. Perrin L, Loizides-Mangold U, Skarupelova S, Pulimeno $\mathrm{P}$, Chanon S, Robert M, et al. Human skeletal myotubes display a cell-autonomous circadian clock implicated in basal myokine secretion. Molecular metabolism. 2015. 4(11):834-45.

20. So B, Kim HJ, Kim J, Song W. Exercise-induced myokines in health and metabolic diseases. Integrative Medicine Research. 2014 Dec 31;3(4):172-9.

21. Kim HJ, So B, Choi M, Kang D, Song W. Resistance exercise training increases the expression of irisin concomitant with improvement of muscle function in aging mice and humans. Experimental gerontology. 2015. 70:11-7.

22. Tabak O, Simsek G, Erdenen F, Sozer V, Hasoglu T, Gelisgen $\mathrm{R}$, et al. The relationship between circulating irisin, retinol binding protein-4, adiponectin and inflammatory mediators in patients with metabolic syndrome. Archives of Endocrinology and Metabolism. 2017. In press.

23. Zhao J, Su Z, Qu C, Dong Y. Effects of 12 Weeks Resistance Training on Serum Irisin in Older Male Adults. Frontiers in physiology. 2017;8. In press.

24. Hecksteden A, Wegmann M, Steffen A, Kraushaar J, Morsch A, Ruppenthal S, et al. Irisin and exercise training in humans-results from a randomized controlled training trial. BMC medicine. 2013. 11(1):235.

25. Pekkala S, Wiklund PK, Hulmi JJ, Ahtiainen JP, Horttanainen M, Pöllänen E, et al. Are skeletal muscle FNDC5 gene expression and irisin release regulated by exercise and related to health? The Journal of physiology. 2013. 591(21):5393-400. 
26. Kim HJ, Lee HJ, So B, Son JS, Yoon D, Song W. Effect of aerobic training and resistance training on circulating irisin level and their association with change of body composition in overweight/obese adults: a pilot study. Physiological Research. 2016. 65(2):271-9.

27. Moraes C, Leal VO, Marinho SM, Barroso SG, Rocha GS, Boaventura GT, et al. Resistance exercise training does not affect plasma irisin levels of hemodialysis patients. Hormone and Metabolic Research. 2013. 45(12):900-4.

28. Ellefsen S, Vikmoen O, Slettaløkken G, Whist JE, Nygård H, Hollan I, et al. Irisin and FNDC5: effects of 12-week strength training, and relations to muscle phenotype and body mass composition in untrained women. European journal of applied physiology. 2014. 114(9):1875-88.

29. Zhang J, Zhang W. Can irisin be a linker between physical activity and brain function? Biomolecular Concepts. 2016. 7(4):253-8.

30. Polyzos SA, Kountouras J, Anastasilakis AD, Geladari EV, Mantzoros CS. Irisin in patients with nonalcoholic fatty liver disease. Metabolism. 2014. 63(2):207-17.
31. Choi ES, Kim MK, Song MK, Kim JM, Kim ES, Chung WJ, et al. Association between serum irisin levels and non-alcoholic fatty liver disease in health screen examinees. PloS one. 2014. 9(10): e110680.

32. Zelber-Sagi S, Buch A, Yeshua H, Vaisman N, Webb M, Harari G, et al. Effect of resistance training on nonalcoholic fatty-liver disease a randomized-clinical trial. World journal of gastroenterology: WJG. 2014. 20(15):4382-92.

33. Oelmann S, Nauck M, Völzke H, Bahls M, Friedrich N. Circulating irisin concentrations are associated with a favourable lipid profile in the general population. PloS one. 2016. 11(4): e0154319.

34. Buscemi S, Corleo D, Buscemi C, Giordano C. Does iris (in) bring bad news or good news? Eating and Weight Disorders-Studies on Anorexia, Bulimia and Obesity. 2017. 20:1-2

35. Lee HJ, Lee JO, Kim N, Kim JK, Kim HI, Lee YW, et al. Irisin, a novel myokine, regulates glucose uptake in skeletal muscle cells via AMPK. Molecular Endocrinology. 2015. 29(6): 873-81. 